ISSN 0258-7122

Bangladesh J. Agril. Res. 40(1): 35-51, March 2015

\title{
STUDY ON WATER SORPTION ISOTHERM OF SUMMER ONION
}

\author{
MD. MASUD ALAM ${ }^{1}$ AND MD. NAZRUL ISLAM ${ }^{2}$
}

\begin{abstract}
The water sorption characteristics of dehydrated onion and onion solutes composite by vacuum drying (VD) and air drying (AD) were developed at room temperature using vacuum desiccators containing saturated salt solutions at various relative humidity levels (11-93\%). From moisture sorption isotherm data, the monolayer moisture content was estimated by Brunauer-Emmett-Teller (BET) and Guggenheim-Anderson-de Boer (GAB) equation using data up to a water activity of 0.52 and 0.93 respectively. Results showed that in case of non treated samples the monolayer moisture content values $\left(\mathrm{W}_{\mathrm{o}}\right)$ of BET gave slightly higher values than GAB (9.7 vs 8.2) for VD, while GAB gave higher value than BET (11.0 vs 9.8) for $\mathrm{AD}$. It is also seen that the treated and non treated onion slice and onion powder absorbed approximately the same amount of water at water activities below about 0.44 and above 0.44 the treated samples begin to absorb more water than the non treated samples. It was observed that $10-20 \%$ added of sugar gave no change in water sorption capacity while the amount of sorbed water increases with increasing amount added salt for mix onion product.
\end{abstract}

Keywords: BET equation, GAB equation, Monolayer moisture content, Water activity

\section{Introduction}

Summer onion (Allium cepa L.) is one of the most important spice crop grown all the year round in Bangladesh. Even any curry cannot be think without onion. It is used as salad or cooked in various ways in all curries, fried or baked. It has very good medicinal value. Nutritive value of onion varies from variety to variety. It major value is in its flavour. Onion ranks medium in caloric value and minerals, low in protein and very low in vitamins (Pandey, 2004).

Sorption isotherm is considered as one of the most fundamental elements for understanding dehydration process based on the removal of majority of water content in produce (Dauthy, 1995). Sorption isotherm depicts relationship of equlibrium moisture content of products to water activity $\left(\mathrm{a}_{\mathrm{w}}\right)$ which is defined as the ratio of vapour pressure of water in a product (food) to the vapour pressure of saturated water at the same temperature and atmospheric pressure. Since water activity of food affects the rate of biological and chemical reactions, the drying

${ }^{1}$ Senior Scientific Officer, Spices Research Center, Bangladesh Agricultural Research Institute (BARI), Bogra. ${ }^{2}$ Professor, Department of Food Technology and Rural Industries, Bangladesh Agricultural University (BAU), Mymensingh 
process when properly designed could inhibit the growth and reproduction of microorganisms that could lead to decay (Herringshaw, 1997). It also prevents biochemical reactions associated with moisture content and results in nutrient loss and deterioration of product quality including organoleptic properties (Haralampu and karel, 1983 and Okos et al., 1992).

Optimal design of drying and storage process is based on knowledge of moisture sorption isotherms and water activity. Moisture sorption isotherms added to the food isosteric heat of sorption are essential for designing efficient dryers and several other food preserving methods. These parameters are useful for predicting stability changes in produce, selecting packing material and ingredients and estimating the energy required for the drying process (Lee and Labuza, 1975).

The moisture sorption isotherms can be obtained by process either increasing or decreasing moisture content are termed as adsorption isotherm and desorption isotherm respectively. Desorption isotherms generally result in higher values of equilibrium moisture content than adsorption isotherm at a given water activity. and this phenomena is termed as hysteresis (Young and Nelson, 1976). This behaviour is especially exihibited by hygroscopic products. At constant moisture content desorption isotherm gives lower water activity than adsorption path. For safety reason it is advised to determined adsorption isotherm particularly for stored products in a changing external environment.

Many researchers have devised a wide variety of ways for describing sorption isotherms, resulting in a large number of theoretical, semitheoretical and emperical equations (Chirife and Iglesias, 1978). Among these theoretical approaches, the BET theory advanced by Brunauer et al. 1938 has been the most successful and widely used in the food industry due to its simplicity and more easily interpretable results with minimum data input. The theory, generally known as BET theory, utilizes the assumption that Vander waals forces account for sorption of water molecules on product surfaces.

The monolayer sorption and the heat of sorption are important because these values are measures of the molecular level status of the total system as defined by the BET theory. The BET monolayer value has been said to be optimal water content for stability of low-moisture materials (Roos, 1995).

The GAB model was found to be the most suitable for describing the sorption data. The monolayer moisture content was estimated using the BrunauerEmmett-Teller (BET) equation. The BET model (Brunauer et al. 1938) gave the best fit to the data at $a_{w}$ of up to 0.5 (Bell and Labuza, 2000 and Roos, 1995). Guggenheim-Anderson-de Boer (GAB) sorption model introduces a third state of sorbed species intermediates to the tightly bound and free states (Anderson, 1946). 
Hossain et al. (2001) observed that higher sorption isotherms at lower temperature and the modified BET model was found to be the best fit model in the temperature range of $20-25^{\circ} \mathrm{C}$ and relative humidity range of 11 $97 \%$.Therefore, the present study was undertaken to determine relationship between $\mathrm{a}_{\mathrm{w}}$ and quality characteristics of different dried onion and onion solute composites .

\section{Materials and Method}

\section{Sample}

The experiment was conducted in the Department of Food Technology and Rural Industries, Bangladesh Agricultural University (BAU), Mymensingh during the period of January, 2011 to July 2011. Freshly harvested summer onion variety of BARI piaz-2 was procured from Spices Research Center (SRC) of Bangladesh Agricultural Research Institute (BARI) and stored at room temperature. Sucrose and salt were bought from local market. All other chemicals were of reagent grade and collected from the scientific store.

\section{Method}

Onions free of mechanical injury and disease were cleaned and washed with tap water and spread on a perforated tray to drain out excess water and subsequently used for preparation of samples. After peeling onions were cut into slices of approximately $5 \mathrm{~mm}$ thickness by an electric slicer or made into slurry by electric blender before being made into samples. When studying sorption behavior of osmosed samples, onion slices were first osmosed ( $24 \mathrm{hr}$, in appropriate solution) and slices were then either i) directly dried in vaccum dryer at $70^{\circ} \mathrm{C}$ or ii) ground to a slurry before vaccum drying. In some cases the ground slurry was blended with known amount of solutes prior to being vaccum dried.

\section{Determination of Sorption isotherm}

Procedures for determining equilibrium moisture content as influenced by water activity in food materials are described in detail by Gal (1983) and Shatadal and Jayas (2000). The principal methods are gravimetric and menometric/ hygrometric. The gravimetric method is divided into static and dynamic methods. As the static gravimetric method is simple and reliable, procedures noted by Islam (1980) with certain modifications were applied in determining sorption isotherm in this study.

The dehydrated $2 \mathrm{~g}$ onion samples were taken in each crucible. Nine desiccators with nine saturated salt solution (Table-1) were used to determine the equilibrium moisture content for vaccum dried onion at room temperature (about $25^{\circ} \mathrm{C}$ ) over a water activity range 0.11 to 0.93 . The sample and the solution was separated by 
a perforated plate to avoid mixing. The dessicators were evacuated to less than 50 torr. The crusibles were kept in vaccum desiccators over saturated salt solution with two replication. At various intervals, the vacuum was broken with air, the sample weighed and replaced in the desiccators, which was then re-evacuated. After attaining equilibrium the crucible were collected from each desiccators and the equilibrium moisture contents of the dried samples were determined by oven method (AOAC, 2000).

The following salt solutions (Table 1) of known water activity were used for the study.

Table 1. Water activity of saturated salt solution.

\begin{tabular}{c|c}
\hline Saturated salt solution & Water activity $\left(\mathbf{a}_{\mathbf{w}}\right)^{\mathbf{b}}$ \\
\hline $\mathrm{LiCI}^{\mathrm{a}}$ & 0.11 \\
$\mathrm{KC}_{2} \mathrm{H}_{3} \mathrm{O}_{2}{ }^{\mathrm{a}}$ & 0.20 \\
$\mathrm{MgCI}_{2} \cdot 6 \mathrm{H}_{2} \mathrm{O}^{\mathrm{a}}$ & 0.33 \\
$\mathrm{~K}_{2} \mathrm{CO}_{3}{ }^{\mathrm{a}}$ & 0.44 \\
$\mathrm{Mg}\left(\mathrm{NO}_{3}\right)_{2} \cdot 6 \mathrm{H}_{2} \mathrm{O}^{\mathrm{a}}$ & 0.52 \\
$\mathrm{CuCI}_{2}{ }^{a}$ & 0.68 \\
$\mathrm{NaCI}^{\mathrm{a}}$ & 0.75 \\
$\mathrm{KCI}^{\mathrm{a}}$ & 0.85 \\
$\mathrm{KNO}_{3}{ }^{\mathrm{a}}$ & 0.93 \\
\hline
\end{tabular}

i) a indicates all chemicals were of reagent grade

ii) b indicates Labuza et al. (1976)

The BET theory states that sorption behavior can be represented by the following equation, popularly known as BET equation, derived either kinetically from thermodynamic considerations or from statistical mechanics (Adamson, 1963).

$$
\frac{W}{W_{0}}=\frac{C_{a}}{\left(1-a_{w}\right)\left[1+(c-1) a_{w}\right]}-------------------(1)
$$

This may be rearranged as:

$$
\frac{a_{w}}{\left(1-a_{w}\right) W}=\frac{1}{W_{0} C}+\frac{a_{w}(C-1)}{W_{0} C}--------------------(2)
$$

Where

$$
\begin{aligned}
& \mathrm{a}_{\mathrm{w}}=\text { water activity } \\
& \mathrm{W}=\text { moisture content, dry basis }(\mathrm{db})
\end{aligned}
$$




$$
\begin{aligned}
& \mathrm{W}_{0}=\text { monolayer moisture content }(\mathrm{db}) \\
& \mathrm{C}=\text { energy constant }
\end{aligned}
$$

The average heat of sorption, $\Delta \mathrm{H}_{\mathrm{s}}$, is given by,

$$
\Delta \mathrm{H}_{\mathrm{s}}=\mathrm{RT}(\mathrm{Inc})
$$

Where

$$
\begin{aligned}
& \mathrm{R}=\text { gas constant } \\
& \mathrm{T}=\text { absolute temperature }
\end{aligned}
$$

Plotting $\frac{a_{w}}{\left(1-a_{w}\right) W}$ vs. $\mathrm{a}_{\mathrm{w}}$, the monomolecular moisture content and heat of sorption can be determined from the slope and intercept.

Curl et al., (1976) rearranged the classical BET equation give:

$$
\frac{a_{w}}{\left(1-a_{w}\right) W}=\frac{1}{W_{0}}+\frac{1}{C W_{0}}\left(\frac{1-a_{w}}{a_{w}}\right)
$$

From a plot of $\frac{a_{w}}{W\left(1-a_{w}\right)}$ vs. $\frac{1-a_{w}}{a_{w}}$, a straight line is obtained which intersects the ordinate at a point equal to $\frac{1}{W_{0}}$ and the abscissa at a point equal to $-\mathrm{C}$. The use of the rearranged equation enables one to directly estimate the value of $\mathrm{C}$ and $\mathrm{W}_{0}$.

The monolayer sorption and the heat of sorption are important because these values are measures of the molecular level status of the total system as defined by the BET theory. The BET monolayer value has been said to be optimal water content for stability of low-moisture materials (Roos,1995).

The GAB model was found to be the most suitable for describing the sorption data. The monolayer moisture content was estimated using the BrunauerEmmett-Teller (BET) equation. The BET model (Brunauer et al. 1938) gives the best fit to the data at $a_{w}$ of up to 0.5 (Bell and Labuza, 2000 and Roos 1995). The $\mathrm{GAB}$ equation has a similar form as that of BET, but has an extra constant, $\mathrm{K}$ (equation-5). BET is actually a special case of GAB.

The $\mathrm{GAB}$ equation is usually presented in the following form:

$\mathrm{W}=\frac{W_{m} K C a_{w}}{\left(1-K a_{w}\right)\left(1-K a_{w}+C K a_{w}\right)}$ 
Where,

$\mathrm{W}=$ the equilibrium moisture; fraction $(\mathrm{db})$

$\mathrm{W}_{\mathrm{m}}=$ the monolayer moisture content; fraction $(\mathrm{db})$

$\mathrm{C}=$ the $\mathrm{GAB}$ multi-layer constant

$\mathrm{K}=$ factor correcting properties of multilayer with respect to the bulk liquid

The following procedure is suggested by Biozt (1983) to fit data on water activities and equilibrium moisture content.

Equation (5) can be transformed as follows:

Equation (5) can be transformed as follows:

$\frac{a_{w}}{W}=\alpha \mathrm{a}^{2}{ }_{\mathrm{w}}+\beta \mathrm{a}_{\mathrm{w}}+$

Where,

$$
\begin{aligned}
\alpha & =\frac{k}{W_{m}}\left(\frac{1}{C}-1\right) \\
\beta & =\frac{1}{W_{m}}\left(1-\frac{2}{C}\right) \\
\gamma & =\frac{1}{W_{m} C k}
\end{aligned}
$$

Equation (6) indicates that GAB equation is a three-parameter model. The water activity and equilibrium moisture content data are regressed using equitation (6) and values of three coefficients $\alpha, \beta$ and $\gamma$ are obtained. From these coefficients, the values of $\mathrm{K}, \mathrm{W}_{\mathrm{m}}$, and $\mathrm{C}$ can be calculated.

\section{Results and Discussion}

The sorption isotherm is a valuable tool for food researcher for its importance in dehydration process, in packaging and in changing of quality during storage. The sorption isotherm of vaccum oven dried (VD) and air dried (AD) onion, water sorption behaviour as influenced by physical state of onion and onion solute composites, sorption behavior of onion composites as affected by composition and concentration of added solutes and sorption behaviour of onion at different temperature were developed and discussed one by one in the following sections.

Comparison of sorption behaviour of vacuum oven dried and air dried onion slice

Adsorption isotherms for dehydrated onion obtained by VD and AD were developed to determine how the onion product will behave in a confined 
environment. The experimental moisture sorption data obtained corresponding to $\mathrm{a}_{\mathrm{w}}$ values for both VD and AD are presented in Fig. 1.

It is seen that samples absorbed little water particularly at below $\mathrm{a}_{\mathrm{w}}(<0.52)$. Thereafter the water absorption was comparatively higher at water activity $\left(\mathrm{a}_{\mathrm{w}}\right)$ values above 0.52 . Water uptake in both the sample was low upto $0.52 \mathrm{a}_{\mathrm{w}}$, medium in the range of 0.52 to $0.8 \mathrm{a}_{\mathrm{w}}$, while beyond $0.8 \mathrm{a}_{\mathrm{w}}$ water sorption rapidly increases as $\mathrm{a}_{\mathrm{w}}$ approaches 1.0, indicating that the isotherms have three distinct regions as noted by Ouaouich, (2004). Almost similar water sorption behaviour was observed for VD and AD onion slices (Chirife and Iglesias, 1978). However, Kamruzzaman (2005) mentioned that vaccum dried aroids gave higher equilibrium moisture content at each $\mathrm{a}_{\mathrm{w}}$ values except 0.75 . The differences might be due to differences in chemical constituents' composition (Rao and Rizvi, 1986) and structure of the raw material.

The monolayer moisture content was estimated using BET and GAB equation. The BET equation is an extension of the Langmuir relationship that accounts for multilayer coverage.

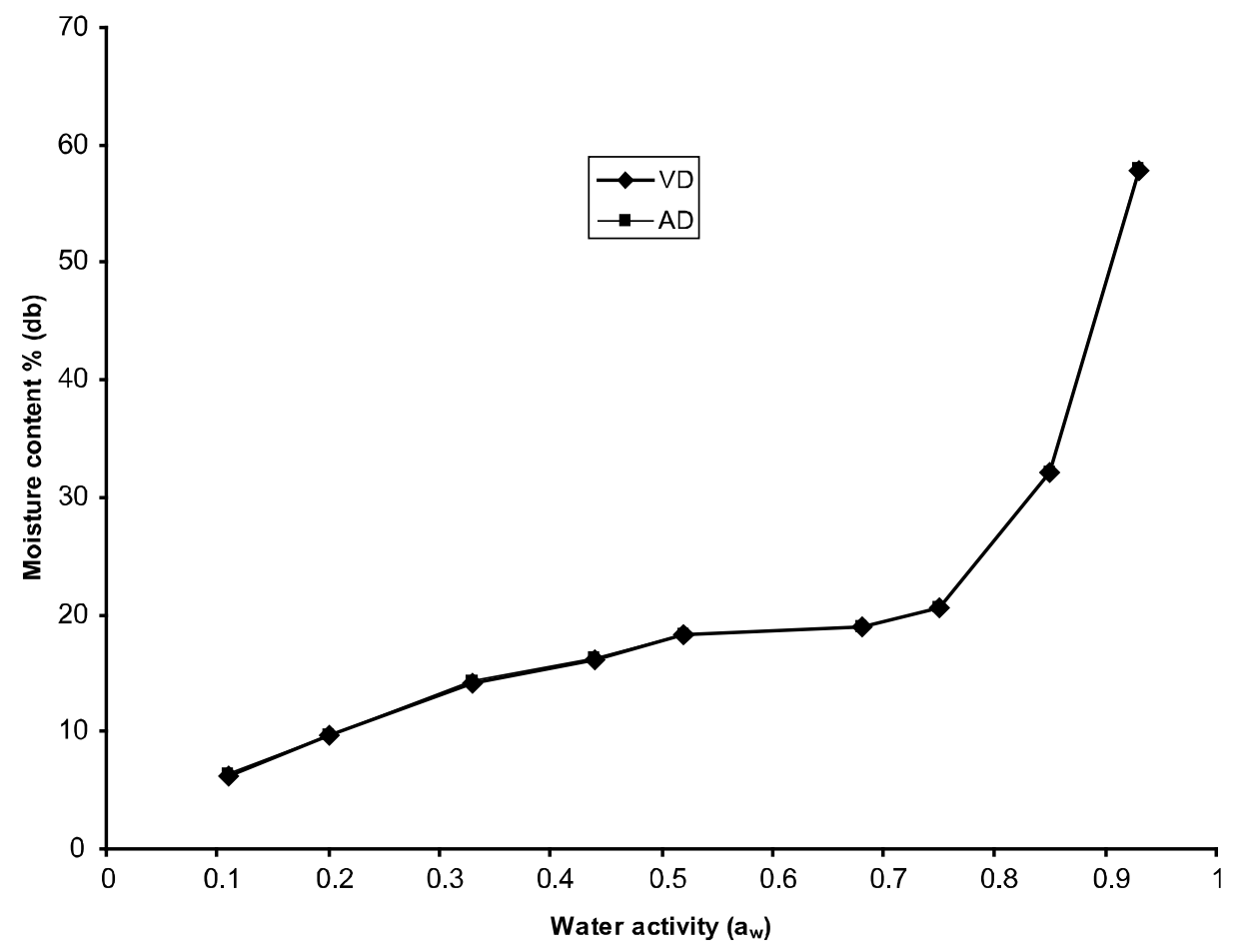

Fig. 1. Graphical presentation of sorption isotherm of vacuum dried and air dried onion 
BET equation (1) was used (for data only up to $a_{w}$ of 0.52 ) to calculate monolayer moisture content $\left(\mathrm{W}_{0}\right)$ and energy constant $(\mathrm{C})$. $\mathrm{W}_{0}$ represents the optimal moisture for maximum storage stability in the dry state. The following equations were obtained for $\mathrm{AD}$ and $\mathrm{VD}$. These equations were then used to calculate $\mathrm{W}_{\mathrm{o}}$ and $\mathrm{C}$ for both $\mathrm{AD}$ and $\mathrm{VD}$ as shown in Table 2.

$$
\begin{aligned}
& \frac{a_{w}}{\left(1-a_{w}\right) W_{0}}=0.0069+0.0959 \mathrm{a}_{\mathrm{w}}(\text { for } \mathrm{VD})-(1) \\
& \frac{a_{w}}{\left(1-a_{w}\right) W_{0}}=0.0068+0.0954 \mathrm{a}_{\mathrm{w}}(\text { for } \mathrm{AD})-(2)
\end{aligned}
$$

Table 2. Monolayer moisture content and energy constant for vacuum dried (VD) and air dried (AD) sample.

\begin{tabular}{l|c|c}
\hline \multicolumn{1}{c|}{ Sample } & $\begin{array}{c}\text { Energy constant } \\
\text { (cal/g-mole) }\end{array}$ & $\begin{array}{c}\text { Monolayer moisture content } \\
\text { (g/100 g solid) }\end{array}$ \\
\hline VD (BET) & 14.90 & 9.73 \\
AD (BET) & 15.03 & 9.79 \\
VD (GAB) & 26.02 & 8.21 \\
AD (GAB) & 22.39 & 10.99 \\
\hline
\end{tabular}

The monolayer moisture content of onion was found to be 9.73 and $9.79 \mathrm{~g}$ water per 100g solid for VD and AD respectively. The calculated monolayer moisture contents are greater than those found by Islam, (1980) who reported 5.5\% moisture content $(\mathrm{db})$ for potato slice and $6 \%$ moisture content $(\mathrm{db})$ for potato powder as $\mathrm{W}_{\mathrm{o}}$. Kamruzzaman (2005), however, found 9.60 and $7.52 \%$ moisture content $(\mathrm{db})$ as $\mathrm{W}_{\mathrm{o}}$ for $\mathrm{VD}$ and $\mathrm{AD}$ of Aroids respectively.

GAB (Guggenheim-Anderson-De Boer) being another important model for describing sorption isotherm behavior. The sorption data of VD and AD onion were analyzed as per equation 6 and the following equation were obtained:

$$
\begin{aligned}
& \frac{a_{w}}{W}=-0.0804 \mathrm{a}_{\mathrm{w}}^{2}+0.0926 \mathrm{a}_{\mathrm{w}}+0.0052 \ldots \ldots \text { For VD } \\
& \frac{a_{w}}{W}=-0.0813 \mathrm{a}^{2}{ }_{\mathrm{w}}+0.0942 \mathrm{a}_{\mathrm{w}}+0.0045 \ldots \ldots \text { For } \mathrm{AD}
\end{aligned}
$$

From Fig. 1 it is seen that at VD and AD onion slices gave about $18 \%$ and $19 \%$ moisture content at $0.6 \mathrm{a}_{\mathrm{w}}$. It may be mentioned here that the current study was concerned with adsorption isotherm so as to avoid risk due to hysteresis effect. 
At same moisture content adsorption path gives higher water activity than desorption path. Thus product dried to safe $a_{w}$ level according to adsorption isotherm will be even safer when it follows desorption path.

The coefficients found $\alpha, \beta$ and $\gamma$ were $-0.0804,0.0926,0.0052$ and -0.0813 , $0.0942,0.0045$ for $\mathrm{VD}$ and $\mathrm{AD}$ respectively (equation 3 and 4). The monolayer moisture content were found 8.21 and $10.99 \mathrm{~g}$ water per $100 \mathrm{gm}$ dry-solids for $\mathrm{VD}$ and $\mathrm{AD}$ respectively, when $\mathrm{K}=0.9$ (Table 2).

Compared to monolayer moisture content of $\mathrm{GAB}$ equation BET gave slightly higher value ( 9.73 vs. 8.21) for $\mathrm{VD}$. On the other side, for $\mathrm{AD}, \mathrm{GAB}$ gave higher value than BET (10.99 vs. 9.79). However, variations are not very high. Considering experimental limitation and design criteria, both models could be utilized. It should, however, be mentioned that BET model is applicable up to $0.52 \mathrm{a}_{\mathrm{w}}$, while GAB is valid up to 0.93 to $0.973 \mathrm{a}_{\mathrm{w}}$ (Roos, 1995 and Talla, 2012) giving an added advantage in predicting sorption behaviour over a wider region. Monolayer moisture content value is important for dry foods and this levels of moisture content is the most stable to chemical reactions (Labuza, 1972; Bluestein and Labuza, 1975).

Considering very low differences in monolayer moisture content values between the VD and AD and from similar sorption behaviour shown in the entire $\mathrm{a}_{\mathrm{w}}$ range ( 0.11 to $0.93 \mathrm{a}_{\mathrm{w}}$ ) by both VD and AD it may be concluded that both AD and VD samples could be used for analyzing sorption behaviour of onion and thus also used for determining end point of drying.

\section{Water sorption behaviour as influenced by physical state of onion and onion solute composites}

Water sorption isotherms were used to demonstrate changes in structure of food materials. Thus the water sorption behavior of onion samples, in the form of slices and powder (prepared from plain and osmosed materials) and onion powder blended with salt were examined to determine if gross onion structure had an influence on water uptake.

The results shown in Fig. 2, indicated that there were no difference in water sorption capacity of slices and powder. At higher water activity, non-treated (plain) slices (the Fig 2 is redrawn from Fig.1 for comparison) begin to absorb more water than powder. No definite deviation as to sorption behaviour was noted for the osmosed samples as well as onion powder blended with salt when compared among themselves. 


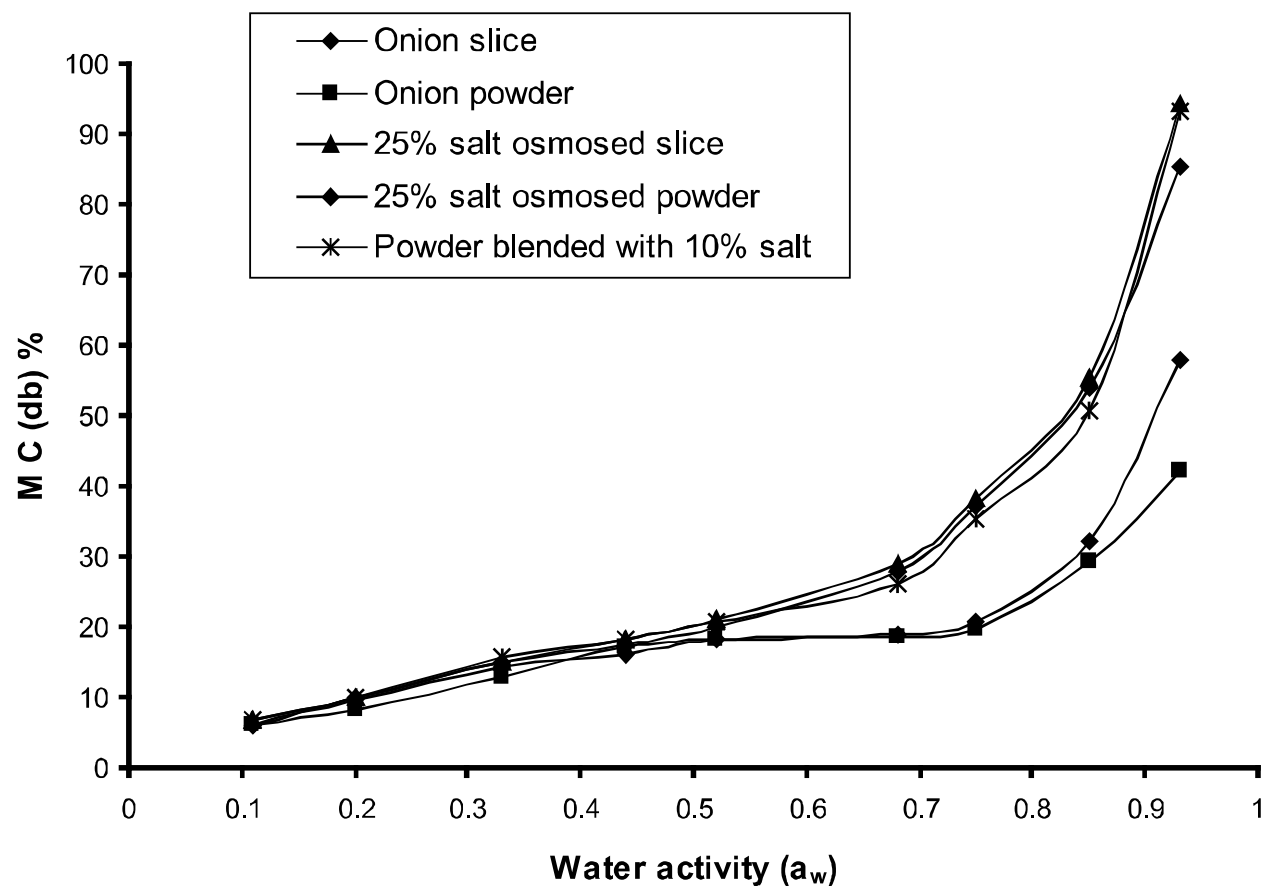

Fig. 2. Water sorption isotherm of onion and onion solute composite

The difference in sorption capacity between slices and powder at higher water activity (at or above $0.75 \mathrm{a}_{\mathrm{w}}$ ) is due to differences in the structural integrity of onion slices and powder. When onion powder is made, the cellular structure and thus also capillaries are somewhat destroyed, whereas minimum damage is caused to the structure when slices are prepared. Since at higher water activity, a large amount of the sorbed water is found in capillaries and intercellular spaces (Labuza, 1968; Nickerson and Sinskey, 1972 and Christian, 1968) of slices could be expected to sorb more moisture than powder. However, this difference may not be critical to the goal of this study since to obtain stable dehydrated product from non treated onion, the moisture content of the product should correspond to water activity below 0.75 .

Comparison between treated samples-osmosed slices, powder from osmosed slices and a powder-salt blend and nontreated samples (onion slices and onion powder) showed that both groups (treated and nontreated samples) absorbed approximately the same amount of water at water activities, below about 0.44 (Fig. 2). At water activities above 0.44 , the treated samples begin to adsorb more water than the nontreated and the difference becomes larger as water activity approaches 1 (Fig. 2). The similarity of water sorption behavior at lower water activity is confirmed by the calculated values of BET and GAB monolayer moisture content (Table 2). The calculation method is the same as noted in the 
section -1. In this cases (except for onion slices) GAB values are higher compared to BET which is in agreement with literature (Timmermann, 2003).

The treated samples having infused or added salt sorbs very little water at water activities below 0.44 and thus the adsorption is primarily due to the polymeric material of the onion tissue. At higher water activities, considerable adsorption takes place which can be attributed to the presence of infused or added salt. This behavior is in good agreement with the literature (Saravacos and Stinchfield, 1965; Islam and Farouk,1981).

From these results, two important conclusions can be drawn. One was that, at water activities of interest relative to the stability of dehydrated onion product, sorption isotherm studies for osmosed materials could be simulated using a model system made of powder (vaccum dried) and salt. The other conclusion was that by treating with salt, the water sorption capacity of the onion product can be made higher so that at water activity values at which the dehydrated products are shelf-stable, the product can be preserved at higher moisture content. This would possibly reduce the drying cost compared to nontreated products, since less moisture removal will be required. As mentioned earlier (section -1) that for experimental reasons, this study has been concerned with the adsorption isotherm. Since the adsorption isotherm has a lower moisture content at each water activity than the corresponding desorption isotherm (which is closer in concept to drying process), it is expected that the dried product would be safely preserved at moisture contents even higher than those presented here (i. e. still at a safe $a_{w}$ level). Accordingly, the values used in this study represent conservative estimates of safe moisture contents.

Table 3. Monolayer moisture content of onion and onion solute composites

\begin{tabular}{c|c|c|c}
\hline Product & $\begin{array}{c}\text { Monolayer } \\
\text { moisture content for } \\
\text { BET equation }\end{array}$ & $\begin{array}{c}\text { Monolayer } \\
\text { moisture content for } \\
\text { GAB equation }\end{array}$ & $\begin{array}{c}\text { Moisture content at } \\
\mathrm{a}_{\mathrm{w}} 0.65\end{array}$ \\
\hline Onion slice $^{\mathrm{a}}$ & 9.73 & 8.21 & 18.843 \\
Onion powder $^{\mathrm{b}}$ & 10.27 & 14.75 & 18.465 \\
Osmosed slice $^{\mathrm{c}}$ & 11.38 & 15.08 & 27.423 \\
Osmosed powder $^{\mathrm{d}}$ & 11.06 & 13.51 & 26.433 \\
Powder, salt blend $^{\mathrm{e}}$ & 11.06 & 15.13 & 25.141 \\
\hline
\end{tabular}

${ }^{\mathrm{a}}$ Onion sliced and vaccum dried.

${ }^{\mathrm{b}}$ Onion sliced and vaccum dried and powdered

${ }^{\mathrm{c}}$ Onion slice osmosed ( $24 \mathrm{hr}$ in $25 \%$ salt solution) and vaccum dried.

${ }^{\mathrm{d} O n i o n}$ sliced osmosed ( $24 \mathrm{hr}$ in $25 \%$ salt solution) and vaccum dried.and powdered

${ }^{\mathrm{e}}$ Vaccum dried onion powder blended with $10 \%$ salt 


\section{Sorption behavior of onion composites as affected by composition and concentration of added solutes}

Different concentration of salt and sugar singly or in combination were used to examine the influence of composition and concentrations of these two osmosis solutes on water sorption behavior of onion at $\mathrm{a}_{\mathrm{w}}$ ranging from 0.52 to 0.93 as below $\mathrm{a}_{\mathrm{w}} 0.52$ added solute (s) does not have additional influence in water uptake (cf. section 2). The results are shown as a series of water sorption isotherms (Fig. 3).

An examination of the sorption isotherms (Fig. 3) showed that 10-20\% added sugar gives slight change above $0.75 \mathrm{a}_{\mathrm{w}}$ in water sorption capacity. On the other hand, addition of salt significantly increases the water sorption capacity of the mixed onion product and the amount of sorbed water increases with increasing amount of added salt. When both salt and sugar are added (each at the 10 percent level) to onion, there appears to be no synergistic effect in so far as water sorption behavior is concerned and the increased amount of water uptake at each water activity is only due to the presence of the added salt.

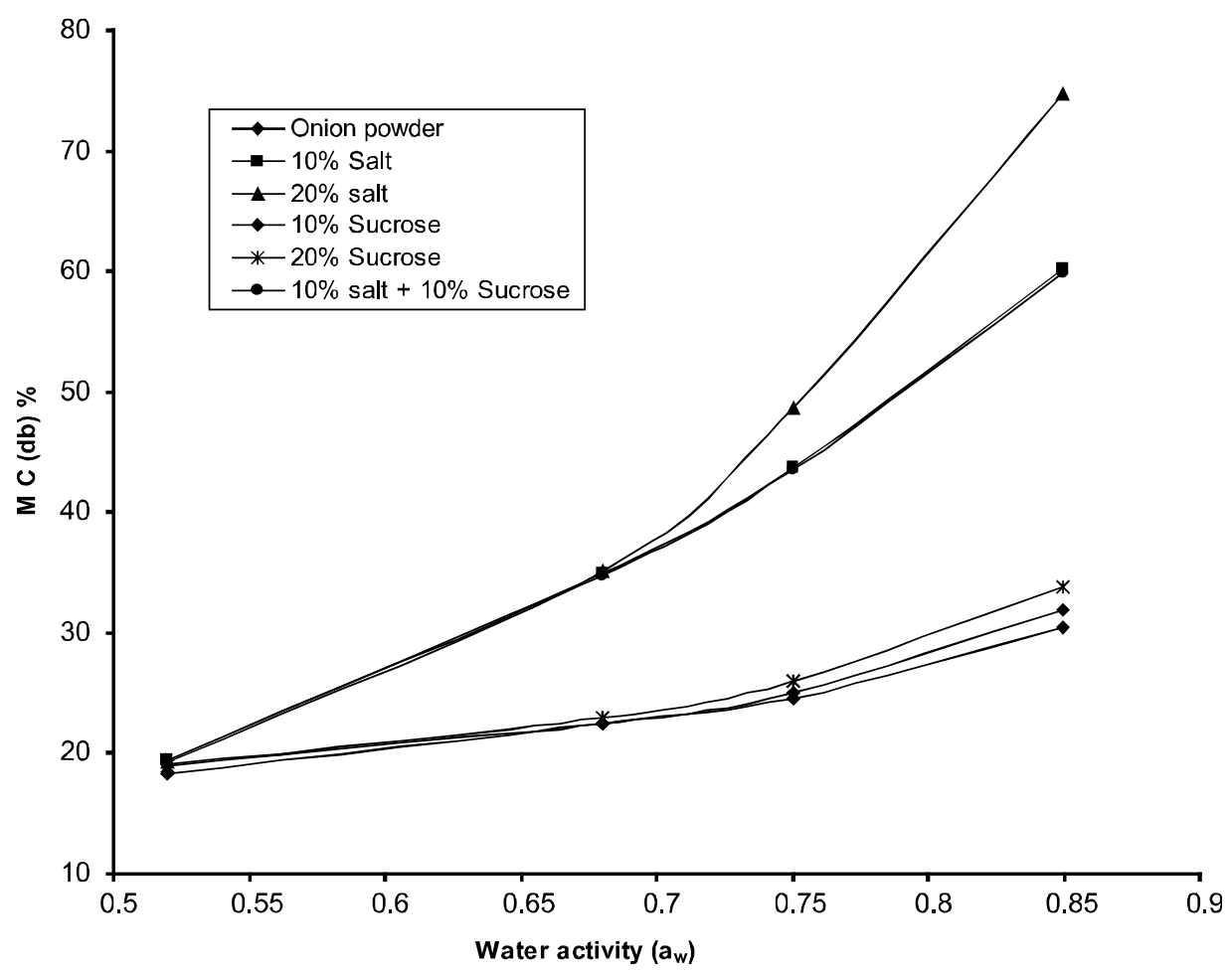

Fig. 3 Effect of composition and concentration of added solutes on water sorption behaviour 
It has been shown (Fig. 2) that the sorption isotherm of onion with added salt begins to deviate from the isotherm for plain onion at water activities above 0.44 . It can now be seen (Fig. 3) that the isotherm for onion with 10 and $20 \%$ added salt deviate from each other at water activities above 0.68 , with samples having $20 \%$ salt levels giving higher moisture content than that with $10 \%$ salt. The steady increase in EMC with increasing salt content, especially at higher water activities, demonstrates the fact that salt is a good water binding agent particularly around its saturation vapor pressure (Islam, 1980). Gal (1971) observed a similar phenomenon, where the equilibrium moisture content of casein increased with increasing salt content, until the protein became saturated with ion pairs. Shibata et al. (1976) demonstrated that the water sorption isotherm of dried noodle is strongly influenced by added salt $(\mathrm{NaCl})$ above an $\mathrm{a}_{\mathrm{w}}$ of 0.6. Islam and Farouk (1981) also showed that at higher water activities, large proportion of water may be sorbed by added salt. While this statement is true for salt, it seems from the above results that it does not hold for sugar-onion blends over the water activity ranges of interest to the stability of dehydrated products ( 0.62 to $0.75 \mathrm{a}_{\mathrm{w}}$ ) as defined by Nickerson and Sinskey (1977).

This implies that only salt would be useful to develop dehydrated onion products having higher equilibrium moisture contents corresponding to the water activity ranges in which dehydrated products are shelf stable. Thus added salt might reduce the cost of drying as the final moisture content required for stability is increased. However, it should be noted that water activity is not the only factor determining the stability of dehydrated product. Presence of solute and/or preservatives, temperature etc. might have significant influence on product stability.

\section{Sorption behaviour of onion at different temperature}

The experimental results of adsorption equilibrium moisture contents of dried onion at temperatures of 10,30 and $50^{\circ} \mathrm{C}$ are presented in Fig. 4. Higher equilibrium moisture contents were found at the lower temperature for the same water activity. For most of the food materials the equilibrium moisture content values decrease with an increase in temperature at a constant water activity. The reason may be that with an increase in temperature the water molecules get activated due to an increase in their energy level, causing them to become less stable and to break away from the water binding site of the food material, thus decreasing the monolayer moisture content. Similar results have been reported by many investigators for food materials low in sugar content (Shatadal and Jayas, 2000). Turhan et al. (1997) presented similar effect of temperature on adsorption 
and desorption isotherms for Turkish red chilli, while Talla (2012) found similar temperature effect for sorption behaviour of rough rice and kilishi respectively. According to the classification of isotherm curves proposed by Brunauer et al. (1940) all of the isotherm curves were found to follow a pattern of sigmoid in shape (type II).

The implication of effect of temperature on sorption behaviour is very crucial particularly for import/export business as packaged food material with constant moisture content would give higher water activity when transported to a country with higher ambient temperature and the stability of product might be at risk.

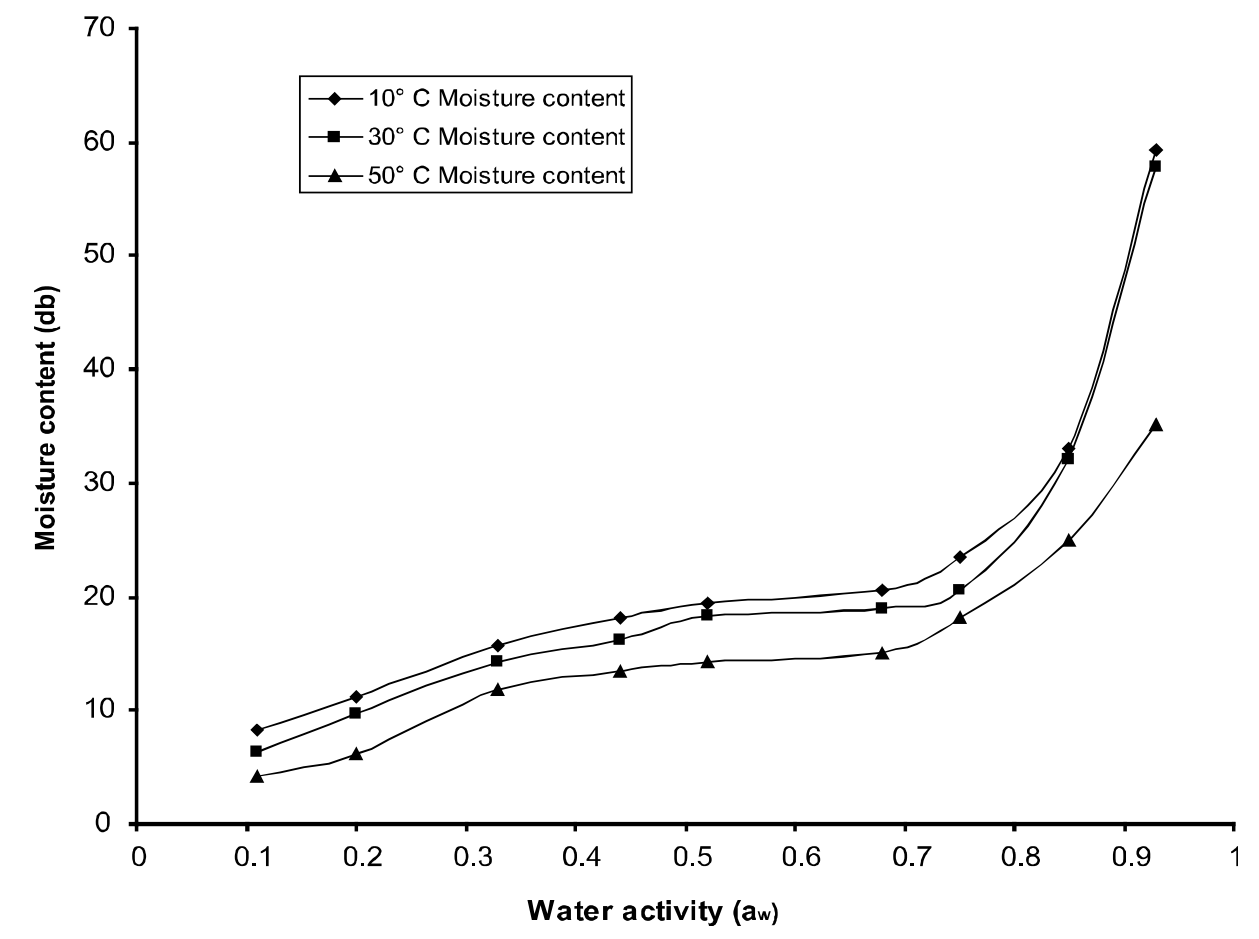

Fig. 4. Sorption isotherm of summer onion at different temperature

Conclusion: AD or VD samples could be used for analyzing sorption behaviour of onion. Except for onion slices, onion sample with infused or added salt gave higher GAB monolayer values compared to BET. Salt is preferred as osmosis solute as it is cheaper and it gives higher EMC compared to sugar particularly at higher $a_{w}$. The higher the salt content following osmosis the higher is the moisture content at water activities of interest to stability of dehydrated products (0.62 to $\left.0.75 \mathrm{a}_{\mathrm{w}}\right)$. The effect of temperature or sorption isotherm demands precautionery measures when packaged dried onion would be transported to a country with higher ambient temperature. 


\section{References}

Adamson, A.W.1963. Physical Chemistry of Surfaces. Inter-science publ. Co. Inc., New York. Pp 571-575.

Anderson, R. B. 1946. Modification of Brunauer, Emmet and Teller equation. J. Am. Chem. Soc. 68: 686-691.

AOAC. 2000. Official Methods of Analysis of the Association of official Analytical Chemist. $17^{\text {th }}$ Ed. Washington D.C.

Bell, L. and T.P.Labuza. 2000. Moisture sorption : practical aspects of isotherm measurement and use. $2^{\text {nd }}$ ed. St. Paul, MN : American Association of Cereal Chemists. Pp. 33-56.

Bluestin, P.M., T.P. Labuza.1975. Effects of moisture removal on nutrients, In Nutritional Evaluation in Food Processing. Harris, RS and Kamas, E.(eds). AVI Publ. Co. Inc., Westport Conn., USA. Pp. 289-323.

Brunauer, S., P. H. Emmett and E.Teller.1938. Adsorption of gases in multimolecular layrs. J. Am. Chem. Soc. 60: 309-319.

Brunauer, S., W.E. Deming and E. Teller. 1940. On a theory of the van der waals adsorption of gas. Journal of American Chemical Society 62: 17-23.

Chirife, J. and H.A. Iglesias. 1978. Equations for fitting water sorption isotherms of foods. Part I: A review. Journal of Food Technology 13: 159-174.

Christian, J.H.B. 1968. Water activity and the growth of microorganisms. In: vol. III of Recent Advances in Food Science. Leitch, J.M.and Rhodes, D.N.(eds).Butterworth's, London. Pp. 146-174.

Dauthy, M. E. 1995. Preservation by reduction of water content: Drying/dehydration and concentration (chapter 5.2). Fruit and Vegetables processing. V5030/E. FAO Agricultural Services Bulletins 119.

Gal, S. 1983. The need for, and practical applications of sorption data. In Physical Properties of Foods, (eds) Jowitt, Ronald et al., Published by Applied Science Publishers, London and New York. Pp. 425.

Gal, S.1971. Hydration of sodium chloride bound by casein at medium water activities. J. Food Sci. 36: 800-803.

Haralampu, S.G. and M. Karel. 1983. Kinetic models for moisture dependence of ascorbic acid and $\beta$-carotene degradation in dehydrated sweet potato. J. Food Sci. 48(6) : 1872-1873.

Herringshaw. D. 1997. Drying Foods. HYG-5347-97. The Ohio State University Extensio Service.

Hossain, M.D., B.K Bala, M.A. Hossain and M.R.A. Mondol. 2001. Sorption isotherms and heat of sorption of pineapple. J. Food Engg. 48(2):103-107. 
Islam, M.N. and S.M. Farouk 1981. Water Sorption Isotherms of Potato and Potato-Salt Composites. Chemical Engineering Research Bulletin, Vol.5, Chemical Engineering Department, BUET, Dhaka. Pp. 11-15.

Islam, M.N. 1980. Use of solar Energy for Development of self-stable Potato Product. Ph.D. Thesis. Royal Veterinary and Agricultural University. Copenhagen. Denmark. Pp. 89-90.

Kamruzzaman, M. 2005. Development of dehydrated aroids product by using mechanical and indirect solar dryer. M.S. thesis, Department of Food Technology and Rural Industries, BAU, Mymensingh, Bangladesh. Pp. 36-39.

Labuza, T. P.1968. Sorption Phenomena in foods. Food Technol. 22(3):15-24.

Labuza, T.P. 1972. Nutrient losses during drying and storage of dehydrated foods. CRC Crit. Rev. Food Technol. 3: 217-240.

Labuza TP, Accott K, Titini SR, Lee RY, Flink JM 1976: Water activity determination : A collaborative study of different methods. Journal of food science 41: 910-917.

Lee, S.H. and T.P. Labuza 1975. Destruction of ascorbic acid as a function of water activity. J. Food Sci. 40: 340-343.

Nickerson, J.A., A.J.Sinskey. 1972. Microbiology of Food and Food processing, pp. 72 75. Elsevier North-Holland, Inc., New York.

Nickerson, J.T. and A.J. Sinskey. 1977. Microbiology of Foods and Food Processing. Elsevier North-Holland, Inc, New York. Pp. 119-121.

Okos, M.R., G. Narsimhan, R. K. Singh and A. C. Weitnauer. 1992. Food Dehydration in Handbook of Food Engineering. edited by D. R. Heldman and D.B.Lund. Marcel Dekker Inc. USA. Pp. 437-562.

Ouaouich, A. 2004. Preservation of fruits and vegetables by drying. Paper No. 29, 9. United Nations Industrial Development Organisation (UNIDO).

Pandey, U.B., L. Sing, S.R. Bhonde. 2004. Onion production in India. Technical bulletin No. 9, NHRDF, Nashik-422011, India. Pp. 1.

Rao, R. and H.A.Rizvi. 1986. A study of desorption isotherms of wheat at $25^{\circ} \mathrm{C}$ and $50^{\circ} \mathrm{C}$. Cereal Chem. 33: 79-91.

Roos, Y. 1995. Water activity and physical state effects on amorphous food stability. J. Food Process Preserv. 16:433-447.

Saravacos, G.D. and R.M.Stinchfield. 1965. Effect of temperature and pressure on the sorption of water vapor by freeze dried food materials. Food Sci. 30(5): 779-786.

Shatadal, P. and D.S. Jayas. 2000. Sorption isotherm of foods. pp 43-58. In: Development of Drying. Volume 1: Food Dehydration. Eds. A.S. Mujumdar and Sirikalaya Suvachittanont. Kastsart University Press, Bangkok, Thailand.

Shibata, S., H.Toyoshima, T. Imai, Y.Inoue.1976. Studies on storage of Japaneese noodle. Part I. Relation between $\mathrm{NaCl}$ content of dried noodle (Udon) and its equilibrium moisture. Nippon Shokuhun Kogyo Gakkaishi 23(9): 397-403. 
Talla, A. 2012. Experimental determination and modelling of the sorption isotherms of kilishi. British journal of applied science \& technology 2(4) 379-389.

Timmermann, E.O. 2003. Multilayer sorption parameters. BET or GAB values. Colloids Surfaces A : Hhysicochem, Long Aspects. 220: 235-260.

Turhan, M., Turhan, Nazan, Sahbaz, Ferhunde. 1997. Drying kinetics of red pepper. Journal of food processing and preservation 21: 209-223.

Young, J.H. and G. L. Nelson. 1976. Theory of hysteresis between sorption and desorption isotherms in biological materials. Transaction of the ASAE 10: 260-263. 